\title{
HUKUM TARIK-MENARIK DALAM NOVEL KLASIK UNDER THE GREENWOOD TREE KARYA THOMAS HARDY
}

The Law of Attraction in Thomas Hardy's Classical Novel Under the Greenwood Tree

\section{Ayu Fitri Kusumaningrum}

Universitas Gadjah Mada

Pos-el: ayufitrikusumaningrum@gmail.com

\section{Naskah diterima: 15 Maret 2021; direvisi: 11 Juni 2021 ; disetujui: 21 Juni 2021}

doi: https://doi.org/10.26499/jentera.v10i1.3492

\begin{abstract}
Abstrak
Penelitian ini bertujuan mengungkapkan upaya-upaya Dick Dewy dalam mendapatkan Fancy Day dalam novel roman klasik Under The Greenwood Tree karya Thomas Hardy. Masalah penelitian adalah bagaimana Dick yang merupakan laki-laki miskin dan tidak terhormat dapat menikahi Fancy yang terpelajar dan tampak tidak terjangkau oleh Dick. Untuk memecahkan masalah dan tujuan penelitian, penelitian ini menggunakan metode kualitatif dan teori pengembangan diri the law of attraction yang dikembangkan Michael J. Losier. Hasil penelitian membuktikan bahwa Dick menerapkan tiga proses dalam the law of attraction untuk mendapatkan Fancy. Dari hasil penelitian dapat disimpulkan bahwa terdapat tiga proses dalam the law of attraction di dalam novel klasik Under the Greenwood Tree, yaitu law of attraction, law of creating, dan law of allowing.
\end{abstract}

Kata-kata kunci: tarik-menarik, Thomas Hardy, roman, merelakan, Michael J. Losier

\section{Abstract}

This study reveals Dick Dewy's efforts to get Fancy Day in the classical romance novel Under the Greenwood Tree by Thomas Hardy. The research problem is how Dick, a poor and dishonorable man, can marry Fancy, who is educated and seems to be out of his league. In order to solve the problem and research objectives, this study uses a qualitative method and a self-help theory, the law of attraction, developed by Michael J. Losier. This research proves that Dick implements three processes in the law of attraction in getting Fancy. From the study results, it can be concluded that there are three processes of the law of attraction in the classical novel Under The Greenwood Tree, such as law of attraction, law of creating, and law of allowing.

Keywords: attraction, Thomas Hardy, romance, allowing, Michael J. Losier

How to Cite: Kusumaningrum, Ayu Fitri. (2021). Hukum Tarik-Menarik dalam Novel Klasik Under The Greenwood Tree Karya Thomas Hardy. Jentera: Jurnal Kajian Sastra, 10(1), 57-72.

Doi: https://doi.org/10.26499/jentera.v10i1.3492

\section{PENDAHULUAN}

Under the Greenwood Tree (1872) karya Thomas Hardy yang diterbitkan pada era Victoria dapat dikatakan sebagai salah satu novel Hardy yang biasanya dikelompokkan dalam karya-karya Hardy yang kurang populer. Dari segi cerita, novel roman ini memang tampak 'manis dan bahagia', berbeda dengan novel-novel Hardy lainnya seperti Jude the Obscure, Far from the Madding Crowd, atau Tess of the d'Urbervilles yang 'kuat dan gelap'. 
Dilabeli sebagai novel yang 'manis dan bahagia', peneliti melihat penelitian terkait karya sastra klasik Under the Greenwood Tree tidaklah sebanyak dan sepopuler novel Hardy lainnya. Meski terlihat seperti bacaan yang ringan dan menyenangkan, peneliti melihat bahwa Under the Greenwood Tree sesungguhnya tetap membawa pesan tersendiri ala Hardy yang dikenal sering mengkritisi masyarakat era Victoria.

Under the Greenwood Tree bercerita tentang seorang anggota paduan suara bernama Dick Dewy yang berhasil menikahi Fancy Day meski Dick berasal dari keluarga musisi dan petani miskin di sebuah desa bernama Mellstock. Dick bukanlah anak dari keluarga kaya dan terpandang di daerah tersebut, berbeda dengan petani kaya bernama Mr. Shiner yang mempunyai kedudukan penting di Mellstock atau Mr. Maybold yang merupakan seorang pendeta baru di daerah itu. Meskipun demikian, Dick-lah yang pada akhirnya berhasil mendapatkan Fancy, bukan Mr. Shiner atau pun Mr. Maybold.

Penelitian ini melihat usaha Dick dalam mendapatkan Fancy menarik untuk diteliti karena pada era Victoria umumnya orang tua akan menikahkan anak perempuan mereka dengan lakilaki yang kaya dan terpandang, hal ini sejalan dengan reaksi Geoffrey Day, ayah Fancy, yang lebih menyukai Mr. Shiner daripada Dick sebagai pendamping hidup Fancy karena merasa Fancy adalah gadis terpelajar yang mendapat pendidikan di kota yang mana hal tersebut membuatnya pantas mendapatkan pendamping hidup yang berasal dari golongan atas. Hal ini juga dapat ditemukan dalam novel-novel roman era Victoria lainnya, seperti Pride and Prejudice (1813), Wuthering Heights (1847), atau Jane Eyre (1847). Rumusan masalah penelitian ini kemudian berusaha untuk menjelaskan bagaimana Dick yang merupakan laki-laki miskin dan tidak terhormat dapat menikahi Fancy yang terpelajar dan tampak tidak terjangkau oleh Dick.

Penelitian ini berbeda dengan yang dilakukan Agista Nidya Wardani (Wardani, 2019) yang meneliti hegemoni maskulinitas pada tiga tokoh laki-laki dalam Under the Greenwood Tree, penelitian Muhammad Nurdin (Nurdin, 2012) yang menganalisis law of attraction dengan segala alasannya dan menjelaskannya dalam perspektif konsep doa dalam Islam, dan penelitian Almasara Mustufabhai Juneja (Juneja, 2020) yang mengkaji unsur hukum tarik-menarik yang terjadi dalam kumpulan puisi The Prophet karya Kahlil Gibran dan novel psikologi The Alchemist karya Paulo Coelho. Penelitian ini mencoba menggabungkan karya sastra klasik dengan teori pengembangan diri (self help) the law of attraction yang dikembangkan Michael J. Losier yang masih jarang ditemukan dalam kajian Sastra Inggris di Indonesia. 
Topik dalam bidang pengembangan diri ini menarik untuk diteliti karena belum banyak menjadi objek penelitian meski prevalensinya sangat besar dan pengaruhnya meluas pada budaya (du Plessis, 2020a). Hal ini disebabkan oleh literatur pengembangan diri yang merupakan genre yang sangat populer (Rimke, 2000). Ada kecenderungan tertentu untuk memandang budaya populer ini sebagai sesuatu yang 'kurang terpelajar' (Rehn, 2008) dan oleh karena itu tidak layak mendapatkan perhatian akademis yang sama seperti bidang-bidang 'serius' lainnya (Parker, 2006). Rehn (2008) menambahkan bahwa daripada mengasumsikan bahwa budaya populer adalah cermin kesenangan semata, kita harus menerima bahwa orangorang membentuk pandangan mereka tentang dunia sebagian berdasarkan budaya populer (Rehn, 2008).

Lebih lanjut, penggunaan novel klasik sebagai objek penelitian ini tidak lepas dari tujuan utama mempelajari karya sastra klasik, yaitu agar karya sastra tersebut dapat terbaca dan dimengerti (Mugi Handayani, 2016). Penelitian yang menggabungkan novel klasik era Victoria dengan teori pengembangan diri abad milenium ini diharapkan dapat memberikan cara baru dalam pembacaan dan pemaknaan sastra klasik, terutama dalam kajian Sastra Inggris di Indonesia.

\section{LANDASAN TEORI}

Membicarakan the law of attraction, banyak teoretikus yang sudah merumuskannya sejak dulu, salah satunya Michael J. Losier. Menurut Losier (2007), the law of attraction bekerja secara universal menarik ke dalam kehidupan kita, apa pun (baik positif maupun negatif) yang kita berikan perhatian, energi, dan fokus (Losier, 2007). Losier menambahkan bahwa hukum tarik-menarik ini sebenarnya adalah hukum alam yang menjelaskan bahwa setiap atom dari keberadaan kita berada dalam respons yang konstan terhadap segala hal yang terjadi di semesta yang luas ini, entah kita mengetahuinya atau tidak (Losier, 2007). Dengan kata lain, sebenarnya semua keinginan kita dapat terwujud berdasarkan hukum tarik-menarik ini karena pada dasarnya diri kita sendiri yang menarik segala hal ke dalam hidup kita, baik hal positif maupun negatif.

Sejatinya, dalam the law of attraction ada tiga hukum atau proses inti yang dapat menjelaskan bagaimana hukum tarik-menarik ini bekerja, yaitu law of attraction (meminta), law of creating (percaya), dan law of allowing (merelakan) (Hicks, 2006). Ketiga proses ini saling berhubungan sehingga untuk memahami atau menerapkan hukum ketiga (law of allowing) misalnya, kita harus memahami hukum pertama dan kedua terlebih dahulu. Di 
samping itu, di antara ketiga proses dalam hukum tarik-menarik ini sebenarnya justru hukum ketiga yang memegang peranan penting. Dapat dikatakan bahwa law of allowing merupakan kunci keberhasilan keseluruhan proses the law of attraction. Sayangnya, justru di hukum ketiga inilah orang sering gagal. Sebagian besar orang kehilangan 'perjalanan getaran mereka' ketika berada di tengah-tengah hukum ketiga. Di sini banyak orang yang 'keluar jalur' sehingga ketiga proses dalam the law of attraction tidak dapat diselesaikan (Mullins, 2008).

Hukum pertama dari keseluruhan proses the law of attraction adalah law of attraction. Hukum pertama ini menjadi langkah penting karena dia menjadi semacam dasar untuk memulai pemahaman mengenai dua hukum lainnya. Inti dari law of attraction adalah meminta (asking). Kita harus tanyakan pada diri kita sendiri, apa yang sebenarnya kita inginkan. Kita harus yakin kita meminta apa pada semesta, apa yang ingin kita tarik ke dalam hidup kita. Apa yang kita fokuskan dalam pemikiran kemudian akan selaras dengan alam semesta dan membawa pikiran itu ke realitas kita. Jadi, langkah pertama dalam membuat hukum tarik-menarik ini bekerja adalah memperjelas apa yang kita inginkan (Losier, 2007).

Setelah kita tahu apa yang kita inginkan, proses selanjutnya adalah menciptakan rasa percaya bahwa kita sudah mendapatkannya. Rhonda Byrne (2007) mengatakan bahwa, "pada saat Anda meminta, dan percaya serta tahu bahwa Anda sudah memilikinya di realitas tidak kasatmata, seluruh semesta bergerak untuk mendatangkannya ke dalam realitas kasatmata Anda (Byrne, 2007)." Byrne menambahkan bahwa kita harus memiliki iman yang utuh dan total. Kita dapat meraih hal-hal yang kita inginkan dengan merasakan dan percaya kita sudah memilikinya. Ketika kita melakukan hal ini, hukum tarik-menarik akan dengan sangat kuat menggerakkan situasi, orang, dan peristiwa kepada kita untuk menerimanya (Byrne, 2007).

Kita sudah tahu apa yang kita inginkan dan kita juga percaya kita sudah mendapatkannya, lalu langkah ketiga sekaligus terakhir adalah merelakan hal tersebut untuk kemudian menerimanya. Menurut Losier (Losier, 2007), allowing atau merelakan secara sederhana berarti tidak adanya getaran negatif dan keraguan adalah getaran negatif. Jika kita ragu dapat memiliki sesuatu, kita mengirim getaran negatif kepada semesta. Getaran negatif inilah yang kemudian menipiskan atau membatalkan getaran positif dari keinginan kita.

Lebih lanjut, Losier mengatakan bahwa perasaan ragu tersebut sering kali diciptakan dari keyakinan yang membatasi diri sendiri atau limiting beliefs (Losier, 2007). Diri kita sendiri yang sering kali justru tidak yakin dapat memiliki keinginan yang kita minta pada semesta. Itulah sebabnya banyak orang justru gagal pada proses ketiga ini karena memang merelakan adalah langkah yang paling sulit dalam proses the law of attraction (Losier, 2007). Dalam 
merelakan, kita tidak perlu memikirkan bagaimana, kapan, atau di mana keinginan kita akan terwujud karena itu adalah tugas semesta untuk membawanya kepada kita. Yang perlu kita lakukan sebenarnya hanyalah mengetahui dengan jelas apa yang kita inginkan, lalu kita percaya kita sudah mendapatkannya (entah bagaimana, kapan, atau di mana), dan akhirnya merelakan hal tersebut untuk kemudian menerimanya di masa depan. Sayangnya, kebanyakan orang malah tidak berhasil di tengah-tengah proses hukum ketiga ini karena munculnya keraguan dalam dirinya.

Losier menegaskan bahwa the law of attraction tidak peduli apakah kita mengingat, berpura-pura, merayakan, bermain, menciptakan, mengeluh atau khawatir. Hukum tarikmenarik ini hanya merespons apa yang ada di dalam 'gelembung getaran' kita (Losier, 2007). Jadi, semakin banyak pikiran dan getaran positif yang kita kirimkan pada semesta, semakin besar pula kesempatan kita dalam mendapatkan apa yang kita inginkan.

\section{METODE PENELITIAN}

Metode penelitian ini adalah metode kualitatif yang menghasilkan data-data deskriptif berupa kata-kata atau kalimat tertulis (Widijanto, 2018) yang mengungkapkan upaya-upaya Dick Dewy dalam mendapatkan Fancy Day dalam novel klasik Under the Greenwood Tree karya Thomas Hardy. Metode ini meliputi dua tahapan sebagai cara kerja yang diterapkan, yaitu pengumpulan data dan analisis data. Data dalam penelitian ini berupa data primer dan data sekunder. Data primer dalam penelitian ini diambil dari novel Under the Greenwood Tree karya Thomas Hardy yang dikaji dengan teori the law of attraction yang dikembangkan Michael J. Losier. Data primer yang dimaksud berupa kata, frasa, kalimat, dan dialog yang terdapat dalam teks novel Under the Greenwood Tree yang berhubungan dengan teori yang dibahas. Data sekunder adalah data-data yang didapat dari luar novel Under the Greenwood Tree yang berkaitan dengan penelitian ini, baik berupa artikel jurnal, buku, koran, majalah, maupun disertasi sebagai data pendukung dalam pembahasan mengenai the law of attraction.

Adapun metode pengumpulan data dalam penelitian ini terbagi menjadi dua: pertama, peneliti membaca dan menyimak secara intensif satuan-satuan teks yang signifikan dalam novel Under the Greenwood Tree berdasarkan teori pengembangan diri Michael J. Losier. Kedua, peneliti menggunakan hasil pembacaan terhadap teori tersebut untuk menentukan penggalanpenggalan teks yang dianggap dapat menyajikan data sesuai dengan tujuan penelitian. Semua variabel yang ditemukan dalam proses pengumpulan data ini kemudian akan dicari hubungannya satu sama lain sehingga menjadi satu kesatuan (Jati, 2020). 
Sedangkan langkah-langkah dalam analisis data adalah sebagai berikut: pertama, peneliti mengidentifikasi karakter-karakter yang akan menjadi fokus penelitian ini. Penelitian ini berfokus pada usaha Dick dalam mendapatkan Fancy sehingga pengidentifikasian karakter didasarkan pada hal tersebut. Kedua, peneliti menemukan tiga hukum atau proses inti dalam the law of attraction yang dilakukan Dick sebagai upayanya mendapatkan Fancy; ketiga proses tersebut adalah law of attraction (meminta), law of creating (percaya), dan law of allowing (merelakan). Dengan membuat interpretasi atau makna dari keseluruhan data (Creswell, 2009), peneliti sampai pada temuan bahwa penelitian ini mengonfirmasi sekaligus memodifikasi gagasan penelitian-penelitian terdahulu terkait the law of attraction.

\section{PEMBAHASAN}

The law of attraction yang biasanya ditemukan dalam buku dan cerita pengembangan diri pada praktiknya juga dapat ditemukan dalam novel klasik Under the Greenwood Tree karya Thomas Hardy. Dengan ditemukannya tiga proses dalam the law of attraction yang dilakukan Dick Dewy untuk mendapatkan Fancy Day dalam Under the Greenwood Tree, penelitian ini melihat bahwa kisah asmara yang ringan dan menyenangkan berlatar era Victoria seperti kisah Dick Dewy dan Fancy Day pun dapat membawa pesan positif seperti buku pengembangan diri era milenium.

\section{Proses Pertama: Law of Attraction}

Sejak pertama kali melihat Fancy Day, Dick Dewy tahu dia menginginkan perempuan itu untuk menjadi teman hidupnya. Ketika pertama kali melihat Fancy saat dia dan rombongan paduan suara bernyanyi keliling Mellstock saat malam Natal, Dick seperti anak kecil yang sedang jatuh cinta; dia hanya diam menatap Fancy. Bahkan, dia tidak menyadari bahwa rombongan paduan suara sudah meninggalkannya. Sikap Dick yang sedang jatuh cinta itu pun terus berlanjut hingga berhari-hari ke depan, apalagi pada saat semua orang akan melakukan ibadah di gereja di mana ada kemungkinan Dick akan bertemu kembali dengan Fancy. Hal tersebut dapat dilihat dalam kutipan berikut.

In the morning, do what he [Dick Dewy] would--go upstairs, downstairs, out of doors, speak of the wind and weather, or what not--he could not refrain from an unceasing renewal, in imagination, of that interesting enactment [...] "Perhaps the new young wom--sch--Miss Fancy Day will sing in church with us this morning," he said.

[...]

They made preparations for going to church as usual; Dick with extreme alacrity, though he would not definitely consider why he was so religious. His wonderful nicety in brushing and cleaning his best light boots had features which elevated it to the rank of an art. Every particle and speck of last week's mud was scraped and brushed from toe and heel; new blacking from the packet was carefully mixed and made use of, regardless of expense. (Hardy, 1994: 27). 
Di pagi hari, dia [Dick Dewy] lakukan apa yang akan dia lakukan--naik ke atas, ke bawah, keluar dari pintu, berbicara tentang angin dan cuaca, atau apa yang tidak--dia tidak bisa menahan diri dari pembaruan tanpa henti, dalam imajinasi, dari undangan yang menarik itu [...] "Mungkin perempuan muda baru--sch-Nona Fancy Day akan bernyanyi di gereja bersama kami pagi ini," katanya.

[...]

Mereka membuat persiapan untuk pergi ke gereja seperti biasa; Dick dengan kesigapan ekstrim, meskipun dia tidak akan mempertimbangkan dengan pasti mengapa dia begitu religius. Sikapnya yang luar biasa dalam menyikat dan membersihkan sepatu bot ringan terbaiknya memiliki fitur yang mengangkatnya ke tingkat seni. Setiap partikel dan setitik lumpur minggu lalu tergores dan disikat dari ujung kaki dan tumit; penggosok sepatu yang baru dari bungkusnya dicampur dengan hati-hati dan digunakan, terlepas dari biayanya.

Sejak pertemuannya dengan Fancy, Dick seperti selalu bersemangat menyambut kegiatan apa saja, termasuk ibadah rutin di gereja. Padahal, Dick sendiri mengaku bahwa dia sebenarnya tidak begitu religius, tapi khusus untuk hari itu dia begitu bersemangat membersihkan sepatu botnya karena dia berpikir Fancy akan datang ke gereja juga. Sikap Dick ini dapat dikatakan bahwa dia sedang meminta Fancy pada semesta. Dia terus memikirkan Fancy dan dengan begitu dia sedang mengirimkan getaran positif kepada semesta bahwa dia benar-benar menginginkan Fancy.

Apa yang dilakukan Dick tersebut sejalan dengan perkataan Byrne (2007) dalam buku pengembangan diri The Secret. Menurut Erik Mygind du Plessis (2020), pesan utama dari The Secret yang mempromosikan the law of attraction adalah bahwa subjek dapat memiliki apa pun yang diinginkannya jika subjek tersebut memikirkannya dengan cukup keras (du Plessis, 2020a). Konsekuensinya, subjek harus berusaha keras mengirimkan energi yang tepat ke alam semesta. Ini karena dalam the law of attraction, subjek menarik segala sesuatu yang masuk ke dalam hidupnya, hal ini dapat berupa apa saja, mulai dari uang, karier, penyakit, hingga hubungan manusia (du Plessis, 2020a).

Dick cast his eyes over his grandfather's shoulder, and saw the vision of the past night enter the porchdoor as methodically as if she [Fancy] had never been a vision at all. A new atmosphere seemed suddenly to be puffed into the ancient edifice by her movement, which made Dick's body and soul tingle with novel sensations. (Hardy, 1994: 29).

Dick mengalihkan pandangannya ke atas bahu kakeknya, dan melihat bayangan tentang malam yang lalu memasuki pintu teras dengan metodis seolah-olah dia [Fancy] tidak pernah menjadi bayangan sama sekali. Suasana baru tiba-tiba tampak membumbung ke bangunan kuno oleh gerakannya, yang membuat tubuh dan jiwa Dick tergelitik dengan sensasi baru.

Dapat dikatakan bahwa getaran atau energi yang dikirimkan Dick kepada semesta semakin lama semakin kuat. Getaran yang Dick kirimkan ini konsisten, hanya Fancy yang ada di pikiran Dick. Kehadiran Fancy, meski bagi orang lain tampak biasa saja, berhasil menggugah Dick dengan segala hal yang melekat pada Fancy. Sedari awal, Dick tahu dan yakin apa yang 
diinginkannya, yaitu Fancy. Dick lalu terus memusatkan fokus, energi, dan perhatiannya hanya kepada Fancy seorang.

Sesuai dengan hukum pertama yang dikemukakan Losier (2007), Dick memperjelas apa yang diinginkannya dan mengirimkan keinginan tersebut kepada semesta. Hukum atau proses pertama dalam the law of attraction ini penting karena dengan menekankan pengiriman pesan yang tepat ke alam semesta, hal tersebut menjadi sebuah strategi yang akan menarik kebahagiaan, keberuntungan, dan kedamaian (du Plessis, 2020b) ke dalam hidup Dick, yang mana di sini hal tersebut adalah gadis pujaan Dick, yakni Fancy.

\section{Proses Kedua: Law of Creating}

Sejak awal Dick tahu bukan hanya dirinya seorang yang ingin mendapatkan Fancy. Nyatanya, ada dua laki-laki lain yang juga berusaha untuk menarik perhatian Fancy. Laki-laki pertama adalah Mr. Shiner, petani kaya di Mellstock, dan kedua adalah Mr. Maybold, pendeta baru di daerah itu. Meskipun dua saingannya dalam mendapatkan Fancy merupakan orangorang terpandang, Dick tidak berkecil hati. Dia selalu berpikiran positif bahwa dia sudah mendapatkan Fancy. Hal tersebut terlihat dalam kutipan berikut:

Fancy was dancing with Mr. Shiner. Dick knew that Fancy, by the law of good manners, was bound to dance as pleasantly with one partner as with another... (Hardy, 1994: 35).

Fancy sedang berdansa dengan Tuan Shiner. Dick tahu bahwa Fancy, menurut hukum sopan santun, terikat untuk menari dengan menyenangkan dengan satu pasangan seperti dengan yang lainnya...

Saat keluarga Dewy mengadakan pesta, Fancy yang merupakan gadis baru di desa itu terlihat menonjol di antara gadis-gadis lain sehingga banyak laki-laki yang ingin berdansa dengannya. Dick dan Mr. Shiner adalah contoh laki-laki yang tampak memperebutkan Fancy untuk berdansa bersama mereka. Dalam merespons hal tersebut, Dick rupanya selalu berpikiran positif. Dia memaklumi Fancy yang terus berdansa bersama laki-laki lain karena saat itu mereka memang sedang berada di suatu pesta dan berdansa dengan siapa saja adalah hal yang biasa. Dick tidak marah melihat Mr. Shiner berdansa bersama Fancy karena dia percaya Fancy melakukan hal tersebut hanya sebatas basa-basi dan kesopanan, bukan karena Fancy menyukai Mr. Shiner.

Sikap percaya Dick ini mencerminkan hukum kedua, yaitu law of creating. Seperti yang dikatakan Byrne (2006), Dick bertindak, berbicara, dan berpikir, seolah-olah dia menerimanya (Fancy) sekarang (Byrne, 2006). Serena Dawn Hashimoto (2018) menambahkan bahwa kombinasi pernyataan (meminta) dan fantasi (percaya) itulah yang menyebabkan terjadinya 
manifestasi (Hashimoto, 2018). Hal tersebut senada dengan klaim Byrne yang menyatakan bahwa dunia luar adalah manifestasi fisik langsung dari pikiran individu (du Plessis, 2020a).

Look at this lovely Fancy! Through the whole past evening touchable, squeezeable-even kissable! For whole half-hours I [Dick] held her so close to me that not a sheet of paper could have been shipped between us; and I could feel her heart only just outside my own, her life beating on so close to mine, that I was aware of every breath in it. (Hardy, 1994: 41)

Lihatlah Fancy yang indah ini! Sepanjang malam lalu dapat disentuh, diremas-bahkan dapat dicium! Selama setengah jam penuh aku [Dick] memeluknya begitu dekat denganku sehingga tidak ada selembar kertas pun yang bisa dikirimkan di antara kami; dan aku bisa merasakan jantungnya hanya di luar punyaku sendiri, hidupnya berdetak begitu dekat denganku, sehingga aku menyadari setiap napas di dalamnya.

Ketika pada akhirnya Dick berhasil ‘mengamankan’ Fancy dalam pesta itu, Dick merasa sudah memiliki Fancy selamanya meski sebenarnya mereka hanya berdansa selama setengah jam. Kedekatan mereka saat berdansa itu juga semakin membuat Dick percaya bahwa dia sudah mendapatkan Fancy; Fancy adalah miliknya seorang, tidak peduli dengan Mr. Shiner, salah satu saingan terberatnya, yang sebelumnya juga berdansa dengan Fancy.

Jack Canfield (2016) berpendapat bahwa untuk melepaskan kekuatan penuh hukum tarikmenarik dan mewujudkan impian seseorang, ada satu unsur utama yang mutlak harus diintegrasikan ke dalam hidup seseorang, yakni tindakan (action) (Canfield, 2016). Ajakan Dick berdansa di pesta tersebut dapat dilihat sebagai tindakan awal yang menunjukkan ketertarikan Dick pada Fancy. Tak hanya percaya bahwa Fancy adalah miliknya, Dick juga melakukan upaya-upaya dalam mendapatkan gadis pujaannya, seperti mengajaknya berdansa dan mengobrol. Hal ini sejalan dengan pernyataan Canfield yang mengatakan bahwa jika seseorang ingin mencapai kesuksesan yang nyata dan langgeng, menciptakan keseimbangan antara perjalanan eksternal dan internal seseorang sangatlah penting (Canfield, 2016). Perjalanan eksternal di sini dimaksudkan pada aksi atau tindakan seseorang, sedangkan perjalanan internal adalah sikap percaya dan pikiran positif yang mencerminkan hukum kedua (law of creating).

"I suppose you know what I mean, sir? You've heard about me and-- Miss Day?"

The red in Maybold's countenance went away: he turned and looked Dick in the face.

"No," he said constrainedly, "I've heard nothing whatever about you and Miss Day."

"Why, she's my sweetheart, and we are going to be married next Midsummer. We are keeping it rather close just at present, because 'tis a good many months to wait; but it is her father's wish that we don't marry before, and of course we must submit. But the time 'ill soon slip along."

"Yes, the time will soon slip along--Time glides away every day-- yes."

$[\ldots]$

"You see, sir," continued the ingenuous Dick, "twill be better in one sense. I shall by that time be the regular manager of a branch $o^{\prime}$ father's business, which has very much increased lately, and business, which we think of starting elsewhere. It has very much increased lately, and we expect next year to keep $a^{\prime}$ extra couple of horses. We've already our eye on one--brown as a berry, neck like a rainbow, fifteen 
hands, and not a gray hair in her--offered us at twenty-five want a crown. And to kip pace with the times I have had some cards prented and I beg leave to hand you one, sir."

"Certainly," said the vicar, mechanically taking the card that Dick offered him. (Hardy, 1994: 129)

"Aku kira Anda tahu apa yang kumaksud, Tuan? Anda pernah mendengar tentangku dan-- Nona Day?" Merah di wajah Maybold hilang: dia berbalik dan menatap wajah Dick.

"Tidak," katanya terbata-bata, "aku tidak pernah mendengar apa pun tentangmu dan Nona Day."

"Wah, dia kekasihku, dan kami akan menikah pada pertengahan musim panas mendatang. Kami merahasiakannya hanya untuk saat ini, karena ini adalah bulan yang baik untuk menunggu; tapi itu adalah keinginan ayahnya agar kami tidak menikah sebelumnya, dan tentu saja kami harus patuh. Tapi waktu 'akan segera berlalu'.

"Ya, waktu akan segera berlalu--Waktu berlalu setiap hari-- ya."

[...]

"Begini, Tuan," lanjut Dick yang cerdik, "Ini akan lebih baik di satu sisi. Aku pada saat itu akan menjadi manajer tetap dari sebuah cabang bisnis ayah, yang akhir-akhir ini sangat meningkat, dan bisnis, yang kami pikir akan dimulai di tempat lain. Ini telah sangat meningkat akhir-akhir ini, dan kami berharap tahun depan untuk memelihara beberapa kuda tambahan. Kami sudah mengincar satu--cokelat seperti buah beri, leher seperti pelangi, lima belas tangan, dan tidak ada uban di tubuhnya--ditawarkan pada kami pada dua puluh lima sen. Dan untuk mengimbangi waktu aku memiliki beberapa kartu yang disodorkan dan aku mohon izin untuk memberikan satu kepada Anda, Tuan."

"Tentu saja," kata pendeta, secara otomatis mengambil kartu yang ditawarkan Dick kepadanya.

Sikap percaya dan pikiran positif Dick juga terlihat ketika Dick dan Mr. Maybold bertemu. Mr. Maybold adalah salah satu saingan terberat Dick lainnya setelah Mr. Shiner. Tidak mengetahui jika Mr. Maybold telah melamar Fancy dan Fancy dalam kegalauannya malah menjawab 'iya' padahal dia juga sedang bertunangan dengan Dick, Dick percaya bahwa Fancy akan menikah dengannya dan mengabarkan hal tersebut pada Mr. Maybold.

The law of attraction memang tidak memberikan ukuran pasti untuk menilai kapan apa yang seseorang pikirkan akan menjadi kenyataan, hukum tarik-menarik ini hanya mengatakan bahwa hal tersebut akan terjadi di masa depan (Hashimoto, 2018). Akan tetapi, hal tersebut tidak menyurutkan niat Dick yang terus percaya bahwa Fancy akan menikah dengannya dan bisnis keluarganya akan terus meningkat di masa depan sehingga dirinya akan menjadi sosok yang pantas bersanding dengan Fancy.

Seperti yang dikatakan Byrne, apa yang seseorang pikirkan, akan seseorang hasilkan. Seluruh hidup seseorang adalah manifestasi dari pikiran-pikiran yang ada di kepalanya (Byrne, 2006). Sejak awal menyukai Fancy, Dick selalu berpikiran positif Fancy memilihnya. Walaupun Dick tahu Fancy memiliki penggemar lain seperti Mr. Shiner dan Mr. Maybold, dia maju terus pantang mundur. Dick tidak membiarkan dua pesaingnya yang lebih kaya dan terpandang itu membuat pikirannya menjadi negatif. Dengan memercayai dan berpikiran positif pada Fancy, dapat dikatakan bahwa Dick berhasil melalui proses kedua dalam hukum tarikmenarik, yaitu law of creating. 


\section{Proses Ketiga: Law of Allowing}

Setelah memastikan apa yang diinginkan lalu percaya sudah memilikinya, langkah terakhir dalam the law of attraction adalah merelakan keinginan tersebut untuk kemudian menerimanya. Hukum ketiga (law of allowing) yang merupakan proses terpenting dalam hukum tarik-menarik ini juga terlihat dalam proses mendapatkan Fancy. Setelah Dick percaya Fancy adalah miliknya, dia merelakan Fancy dengan melamar kekasih hatinya itu untuk kemudian ditolak oleh ayah Fancy. Hal itu dapat dilihat dalam kutipan di bawah ini.

"I've come to ask for Fancy," said Dick.

"I'd as lief you hadn't."

"Why should that be, Mr. Day?"

"Because it makes me say that you've come to ask what ye be'n't likely to have. Have ya come for anything else?"

"Nothing."

[...]

"Well, when I went a-wandering after her mother's death, she lived with her aunt, who kept a boardingschool, till her aunt married Lawyer Green--a man as sharp as a needle-- and the school was broke up. Did ye know that then she went to the training-school, and that her name stood first among the Queen's scholars of her year?"

"I've heard so."

[...]

"That if any gentleman, who sees her to be his equal in polish, should want to marry her, and she want to marry him, he sha'n't be superior to her in pocket. Now do ye think after this that you be good enough for her?"

"No."

"Then good-night t'ee, Master Dewy."

"Good-night, Mr. Day."

Modest Dick's reply had faltered upon his tongue, and he turned away wondering at his presumption in asking for a woman whom he had seen from the beginning to be so superior to him. (Hardy, 1994: 111113).

"Aku datang untuk meminta Fancy," kata Dick.

"Aku yakin kamu tidak."

"Kenapa harus begitu, Tuan Day?"

"Karena itu membuatku mengatakan bahwa kamu datang untuk menanyakan apa yang tidak mungkin kamu miliki. Apakah kamu datang untuk hal lain?"

"Tidak ada."

[...]

"Nah, ketika aku pergi mengembara setelah kematian ibunya, dia tinggal bersama bibinya, yang menjaga sekolah asrama, sampai bibinya menikah dengan Pengacara Green--pria setajam jarum-- dan sekolah itu bubar. Tahukah kamu bahwa kemudian dia pergi ke sekolah pelatihan, dan bahwa namanya berada di urutan pertama di antara para cendekiawan Ratu di tahun itu?"

"Aku pernah mendengarnya."

[...]

"Bahwa jika ada pria, yang melihat dia setara dengannya di Polandia, ingin menikahinya, dan dia ingin menikahinya, dia tidak akan lebih unggul darinya di saku. Sekarang apakah kamu berpikir setelah ini bahwa kamu cukup baik untuknya?"

"Tidak."

"Kalau begitu selamat malam, Tuan Dewy."

"Selamat malam, Tuan Day."

Jawaban Dick yang rendah hati terbata-bata di lidahnya, dan dia berbalik bertanya-tanya pada anggapannya dalam meminta seorang wanita yang dia lihat sejak awal lebih unggul darinya. 
Satu hal yang belum dieksplorasi dalam studi-studi pengembangan diri mengenai the law of attraction adalah belum adanya contoh kasus di mana kita sudah berhasil melalui proses pertama dan kedua, tetapi ketika berada di tengah-tengah proses ketiga, kita mendapatkan penolakan pada mulanya. Penolakan ini tidak lantas membuat kita menyerah atau 'keluar jalur' (Mullins, 2008), akan tetapi kita tetap percaya, tidak ada keraguan, dan merelakan keinginan kita sehingga pada akhirnya semesta benar-benar memberikan keinginan kita.

Dick dapat dikatakan adalah salah satu contoh kasus di mana ketika sedang berada di tengah-tengah hukum ketiga, dia mendapatkan penolakan. Ayah Fancy tidak setuju jika putrinya harus menikah dengan Dick karena di mata ayah Fancy, dia tidak memiliki kedudukan penting atau harta yang melimpah. Penolakan ini sedikit banyak sudah dapat diprediksi oleh Dick karena dari pertama menyukai Fancy, dia tahu dia sedang berurusan dengan siapa. Akan tetapi, hal tersebut tidak membuat nyali Dick ciut, dia tetap melamar Fancy dengan berani.

Apa yang dilakukan Dick ini dapat dikatakan merupakan komitmen Dick pada Fancy. Menurut Marshall Brown (2007), komitmen, pada dasarnya, menyiratkan pilihan. Memilih sesuatu berarti tidak memilih sesuatu yang lain (Brown, 2007). Berbeda dengan Fancy yang membiarkan pilihannya terbuka, sedari awal Dick menunjukkan komitmennya dengan hanya memfokuskan diri pada Fancy, bahkan setelah lamaran Dick ditolak ayah Fancy. Komitmen Dick ini menandakan bahwa sejatinya Dick telah berhasil melalui proses terberat dalam hukum tarik-menarik, yaitu hukum ketiga (law of allowing) atau merelakan.

"You think I've been cruel to thee in saying that that penniless Dick o' thine sha'n't marry thee, I suppose?" No answer.

"Well, you know, Fancy, I do it for the best, and he isn't good enough for thee. You know that well enough." Here he again looked at her as she lay. "Well, Fancy, I can't let my only child die; and if you can't live without en, you must ha' en, I suppose."

" $O$, I don't want him like that; all against your will, and everything so disobedient!" sighed the invalid.

"No, no, 'tisn't against my will. My wish is, now I d'see how 'tis hurten thee to live without en, that he shall marry thee as soon as we've considered a little. That's my wish flat and plain, Fancy. There, never cry, my little maid! You ought to ha' cried afore; no need o' crying now 'tis all over. Well, howsoever, try to step over and see me and motherlaw to-morrow, and ha' a bit of dinner wi' us."

"And--Dick too?"

"Ay, Dick too, 'far's I know."

"And WHEN do you think you'll have considered, father, and he may marry me?" she coaxed.

"Well, there, say next Midsummer; that's not a day too long to wait." (Hardy, 1994: 119-120)

"Kamu pikir aku telah kejam kepadamu dengan mengatakan bahwa Dick yang tidak punya uang tidak akan menikahimu, kan?"

Tidak ada jawaban.

"Yah, kamu tahu, Fancy, aku melakukannya untuk yang terbaik, dan dia tidak cukup baik untukmu. Kamu cukup tahu itu." Di sini dia kembali menatapnya saat dia berbaring. "Yah, Fancy, aku tidak bisa membiarkan satu-satunya anakku mati; dan jika kamu tidak bisa hidup tanpanya, kamu harus memilikinya, kukira." 
" $O$, aku tidak ingin dia seperti itu; semua bertentangan dengan keinginanmu, dan semuanya sangat tidak patuh!" mendesah yang tidak valid.

"Tidak, tidak, 'tidak bertentangan dengan keinginanku. Harapanku adalah, sekarang aku akan melihat betapa menyakitkannya kamu untuk hidup tanpanya, bahwa dia akan menikahi kamu segera setelah kami mempertimbangkan sedikit. Itu keinginanku datar dan polos, Fancy. Sudah, jangan pernah menangis, anak kecilku! Kamu harus menangis sebelumnya; tidak perlu menangis sekarang 'ini semua sudah berakhir. Yah, bagaimanapun, cobalah untuk melangkah dan menemuiku dan ibu mertua besok, dan makan malam bersama kami."

"Dan-Dick juga?"

"Yah, Dick juga, sejauh yang aku tahu."

"Dan KAPAN menurut Ayah akan mempertimbangkannya, dan dia boleh menikah denganku?" dia membujuk.

"Nah, itu, katakanlah pertengahan musim panas berikutnya; itu bukan hari yang terlalu lama untuk ditunggu."

Setelah ayahnya menolak lamaran Dick, Fancy melancarkan aksi mogok makan. Dia pun jatuh sakit dan karena tidak tega melihat putri tunggalnya menderita, ayah Fancy lalu memberikan restu atas rencana pernikahan Fancy dan Dick. Sesuai dengan hukum tarikmenarik, semestalah yang kemudian bekerja mendatangkan Fancy kepada Dick setelah Dick berhasil melalui ketiga proses hukum tersebut. Bukti lain di mana lagi-lagi semesta membawa Fancy kepada Dick juga dapat dilihat dalam kutipan berikut.

"DEAR MR. MAYBOLD, --I have been thinking seriously and sadly through the whole of the night of the question you put to me last evening and of my answer. That answer, as an honest woman, I had no right to give.

"It is my nature--perhaps all women's--to love refinement of mind and manners; but even more than this, to be ever fascinated with the idea of surroundings more elegant and pleasing than those which have been customary. And you praised me, and praise is life to me. It was alone my sensations at these things which prompted my reply. Ambition and vanity they would be called; perhaps they are so.

"After this explanation I hope you will generously allow me to withdraw the answer I too hastily gave.

"And one more request. To keep the meeting of last night, and all that passed between us there, for ever a secret. Were it to become known, it would utterly blight the happiness of a trusting and generous man, whom I love still, and shall love always.--Yours sincerely,

"FANCY DAY. (Hardy, 1994: 131)

"KEPADA TUAN MAYBOLD, --Saya telah memikirkan pertanyaan yang Anda ajukan kepada saya tadi malam dan jawaban saya dengan serius dan sedih sepanjang malam. Jawaban itu, sebagai wanita jujur, saya tidak berhak memberi.

"Sudah menjadi sifat saya-mungkin semua wanita-menyukai kemurnian pikiran dan tata krama; tetapi bahkan lebih dari ini, terpesona dengan gagasan tentang lingkungan yang lebih elegan dan menyenangkan daripada yang biasa. Dan Anda memuji saya, dan pujian adalah hidup bagi saya. Hanya sensasi saya pada hal-hal ini yang mendorong jawaban saya. Hal tersebut akan disebut ambisi dan kesombongan; mungkin memang begitu.

"Setelah penjelasan ini saya harap Anda dengan murah hati mengizinkan saya untuk menarik kembali jawaban yang saya berikan dengan tergesa-gesa.

"Dan satu permintaan lagi. Untuk menjaga pertemuan tadi malam, dan semua yang terjadi di antara kita di sana, selamanya menjadi rahasia. Jika itu diketahui, itu akan benar-benar merusak kebahagiaan seorang pria yang percaya dan murah hati, yang masih saya cintai, dan akan selalu saya cintai.

-- Hormat saya,

"FANCY DAY. 
Kecerobohan Fancy menerima lamaran Mr. Maybold di saat ayahnya sudah merestui dan merencanakan pernikahannya dengan Dick, membuat Fancy harus memilih salah satu di antara kedua laki-laki yang melamarnya: Mr. Maybold si pendeta terhormat atau Dick si petani miskin. Pada akhirnya Fancy memilih Dick karena sejak awal dia memang mencintai Dick meski lakilaki itu bukanlah orang terpandang atau berasal dari keluarga terhormat. Fancy membatalkan jawaban atas lamaran Mr. Maybold dan mengatakan kepada Mr. Maybold bahwa sesungguhnya dia mencintai Dick.

Sesuai dengan pernyataan Losier (2007), semakin banyak pikiran dan getaran positif yang Dick kirimkan pada semesta, semakin besar pula kesempatan Dick dalam mendapatkan apa yang dia inginkan. Meskipun bersaing dengan laki-laki lain yang memiliki nama baik dan harta, kesempatan Dick dalam mendapatkan Fancy justru semakin terbuka lebar, sejalan dengan kerja hukum ketiga.

Keputusan Fancy yang akhirnya memilih Dick ini kemudian dapat dikatakan merupakan bukti kerja semesta yang membawa Fancy kepada Dick. Fancy bisa saja memilih Mr. Maybold karena harta dan nama Mr. Maybold menawarkan kenyamanan tersendiri seperti yang diungkapkan Fancy dalam surat. Akan tetapi, pada akhirnya Fancy justru memilih Dick yang tidak memiliki harta dan nama. Seperti yang dikatakan Kerry Weber, cinta, ternyata, bukanlah sains (Weber, 2014). Baik Mr. Maybold, ayah Fancy, maupun Dick, tidak akan pernah mengerti apa yang dirasakan Fancy karena hanya Fancylah yang memahami hatinya.

Pendek kata, pilihan Fancy ini adalah jawaban semesta atas proses hukum tarik-menarik yang berhasil dilakukan Dick sampai proses terpentingnya, yaitu hukum ketiga. Setelah memastikan bahwa hanya Fancy yang diinginkannya, lalu percaya Fancy adalah miliknya, Dick benar-benar merelakan Fancy. Dick tidak peduli bagaimana, kapan, atau di mana keinginannya terwujud karena itu bukanlah tugasnya, itu adalah tugas semesta. Semesta memang bekerja untuk kemudian membawa Fancy kepada Dick meski awalnya ayah Fancy menentang pernikahan keduanya. Pada akhirnya, Dick berhasil mendapatkan Fancy karena dia berhasil melalui langkah terberat dari hukum tarik-menarik, yaitu merelakan.

\section{SIMPULAN}

Penelitian ini melihat bahwa rupanya Dick Dewy menerapkan the law of attraction dalam mendapatkan Fancy Day seperti yang diungkapkan dalam novel klasik Under the Greenwood Tree. Pertama, Dick memusatkan keinginannya (yaitu Fancy), lalu kedua, dia percaya Fancy sudah menjadi miliknya, dan setelah itu, ketiga, dia merelakan Fancy untuk kemudian 
mendapatkannya. Sedikit berbeda dengan keseluruhan proses hukum tarik-menarik yang sudah dijelaskan, terdapat satu bagian dalam proses Dick mendapatkan Fancy yang belum dikembangkan dalam studi-studi pengembangan diri terdahulu. Sebelum benar-benar mendapatkan Fancy, Dick mengalami penolakan ketika berada di tengah-tengah proses ketiga (law of allowing). Penolakan ini tidak serta-merta membuat Dick menyerah atau 'keluar jalur' dari seluruh proses hukum tarik-menarik; dia tetap menginginkan Fancy, percaya Fancy adalah miliknya, serta tidak ada keraguan dalam dirinya saat merelakan Fancy.

Penelitian ini menemukan bahwa setelah penolakan yang dialami oleh Dick, semesta justru bekerja mendatangkan Fancy kepada Dick. Hal tersebut terjadi karena Dick berhasil melalui langkah terberat dari hukum tarik-menarik, yaitu merelakan. Dick tidak peduli bagaimana, kapan, atau di mana keinginannya terwujud, dia merelakan keinginannya. Karena berhasil melalui keseluruhan proses dalam hukum tarik-menarik, Dick menikah dengan Fancy. Dapat dikatakan bahwa ketiga proses dalam hukum tarik-menarik yang tercermin dalam upaya Dick ini menjelaskan bagaimana Dick yang merupakan laki-laki miskin dan tidak terhormat pada akhirnya dapat menikah dengan Fancy yang terpelajar dan tampak tidak terjangkau oleh Dick.

\section{DAFTAR PUSTAKA}

Brown, M. (2007). Attraction: Getting What You Want to Come to You Published by: American Water Resources Association ATTRACTION : GETTING WHAT YOU WANT TO COME TO YOU. 9(3), 28-29.

Byrne, R. (2006). The Secret. Atria Books.

Byrne, R. (2007). The Secret: Rahasia (e-book). Gramedia Pustaka Utama. Canfield, J. (2016). 5 Secrets To Activating The Laws of Attraction. LifeHealthPro. Creswell, J. W. (2009). Research design: Qualitative, quantitative, and mixed methods approaches (3rd ed). SAGE Publications, Inc.

du Plessis, E. M. (2020). 'How to Perpetuate Problems of the Self: Applying Foucault's Concept of Problematization to Popular Self-Help Books on Work and Career.' Culture and Organization. https://doi.org/https://doi.org/10.1080/14759551.2020.1752691

du Plessis, E. M. (2020). 'Be a model, not a critic': Self-help culture, implicit censorship and the silent organization. Organization. https://doi.org/10.1177/1350508420939230

Hardy, T. (1994). Under the Greenwood Tree (e-book) (Wordsworth).

Hashimoto, S. D. (2018). Prophetic performatives: the New Age's pending efficacy through self-prophecy. Culture and Religion, 19(2), 217-234. https://doi.org/10.1080/14755610.2018.1444652

Hicks, E. and J. (2006). The law of attraction. Hay House.

Jati, G. P. (2020). Transmisi Memori dan Wacana Rekonsiliasi dalam Cerpen "Perempuan Sinting Di Dapur” Karya Ugoran Prasad: Kajian Postmemory. JENTERA: Jurnal Kajian Sastra, 9(1), 28-42.

Losier, M. J. (2007). Law of attraction: The Science of Attracting More of What You Want and Less of What You Don't. Wellness Central. 
Mugi Handayani, P. (2016). Sambutan Novel Java Joe: Rahasia Kebangkitan Rara Jonggrang Karya J.H Setiawan terhadap Teks Babad Prambanan. JENTERA: Jurnal Kajian Sastra, 5(2), 59-73.

Mullins, E. (2008). "The Process of the law of attraction and The 3rd Law, Law of allowing" paper submitted in partial fulfillment of the requirements for the Master of Science Degree in Training and Development.

Nurdin, M. (2012). The law of attraction dan doa dalam islam. Dialogia: Jurnal Studi Islam Dan Sosial, 10(2), 227-240. https://doi.org/https://doi.org/10.21154/dialogia.v10i2.314

Parker, M. (2006). 'The Counter Culture of Organisation: Towards a Cultural Studies of Representations of Work.' Consumption, Markets and Culture, 9(1), 1-15.

Rehn, A. (2008). 'Pop (Culture) Goes the Organization: On Highbrow, Lowbrow and Hybrids in Studying Popular Culture within Organization Studies.' Organization, 15(5), 765783.

Rimke, H. M. (2000). 'Governing Citizens through Self-Help Literature.' Cultural Studies, 14(1), 61-78.

Wardani, A. N. (2019). Hegemoni Maskulinitas dalam Under The Greenwood Tree Karya Thomas Hardy. Satwika : Kajian Ilmu Budaya Dan Perubahan Sosial, 2(2), 68. https://doi.org/10.22219/satwika.vol2.no2.68-78

Weber, K. (2014). Laws of Attraction: Love and loss in 'The Theory of Everything.' America, $30-31$.

Widijanto, Tjahjono. (2018). Dunia Halus Mistis Jawa dan Fantasi Magis Ternate dalam Godlob Dan Cala Ibi. JENTERA: Jurnal Kajian Sastra, 7(1), 102-129. 